http://garmian.edu.krd

https://doi.org/10.24271/garmian.141

\title{
Studying the Effects of Kaolinite Additions on the Properties of Ceramic Bodies Prepared from Alumina Powder by Slip Casting Technique
}

\author{
Sabah A. Salman*, Sheahab A. Z. Al-jubouri ${ }^{* * *}$ and Haydar Ali Salman Al-obaidy* \\ * Department of Physics, College of Science, University of Diyala, Diyala, Iraq. \\ ** Applied Science Department, University of Technology, Baghdad, Iraq.
}

\begin{abstract}
In this work, physical phenomena related to the growth and phase formation of alumina powder are investigated by experiments and computer calculations. The specimens were formed by slip casting technique. These specimens were fired at various temperatures $(500,1100$ and 1600) ${ }^{\circ} \mathrm{C}$. Alumina samples with different dopant percentages were prepared to study their various physical and mechanical properties. Before casting, slurries with (60 wt. \%) solid content and different percentages of dopant additions were prepared. The dopant used here is kaolinite with $(0,5,10$ and 15$)$ percentage addition, where kaolinite is one of many types of raw materials that have plasticity and advantage of securing. Sodium carboxymethylcellulose (Na-CMC) solution was used as dispersant. The stability of the slip clearly depends on the percentage of dispersant added and the best ratio is found to be $(0.33 \mathrm{ml})$ for each gram of solids. Kaolinite percentage increase leads to decreasing the porosity and water absorption but it leads to increase density, thermal conductivity and all the mechanical properties.
\end{abstract}

\section{Keywords: Slip casting, Alumina, Kaolinite, Na-CMC.}

\section{Introduction:}

Some of the mechanical properties of ceramics have always been attractive to manufacturers. Their hardness, durability, and ability to operate effectively at high temperatures are unsurpassed by any metal, but their brittleness and difficulty in manufacturing complex shapes have been repelling factors to manufacturers [1]. 
Slip casting is an old and traditional process which comprises casting a slip (slurry) of particles such as ceramic particles, metallic particles, etc. which can be used as long as they are insoluble in solvent, and in particularly a method suitable for forming a cast article of high quality complex shaped bodies [2].

The common casting methods involve drain casting and solid casting; hollow bodies such as crucibles are prepared by drain casting whereas non hollow bodies are prepared by solid casting. Casting process begins by filling a mould with ceramic slurry having a pourable consistency. These common casting methods are based on colloidal system in which removal of the liquid is used to consolidate particles suspended in slurry. In slip casting consolidation of particles is accomplished as the liquid flows through a porous medium under a pressure gradient [3].

Aluminum oxide (alumina; $\mathrm{Al}_{2} \mathrm{O}_{3}$ ) has advantages such as its thermal, chemical, and physical properties when compared with several ceramics materials, and is widely used for firebricks, abrasives and integrated circuit (IC) packages [2, 4].

By slip casting alumina can be used as parts for high temperature operated instruments, furnace parts, turbine and boiler parts, machine parts and gears also surgical and medical parts [5].

\section{Experimental Procedure:}

For the preparation of samples through slip casting: fine powders were used such as micro alumina and kaolinite; Dispersant used is Sodium carboxymethylcellulose (Na-CMC); Solvent used is distilled water and the Plaster of Paris moulds were used for the casting. The flow chart of the slip casting process is shown in figure (1). 


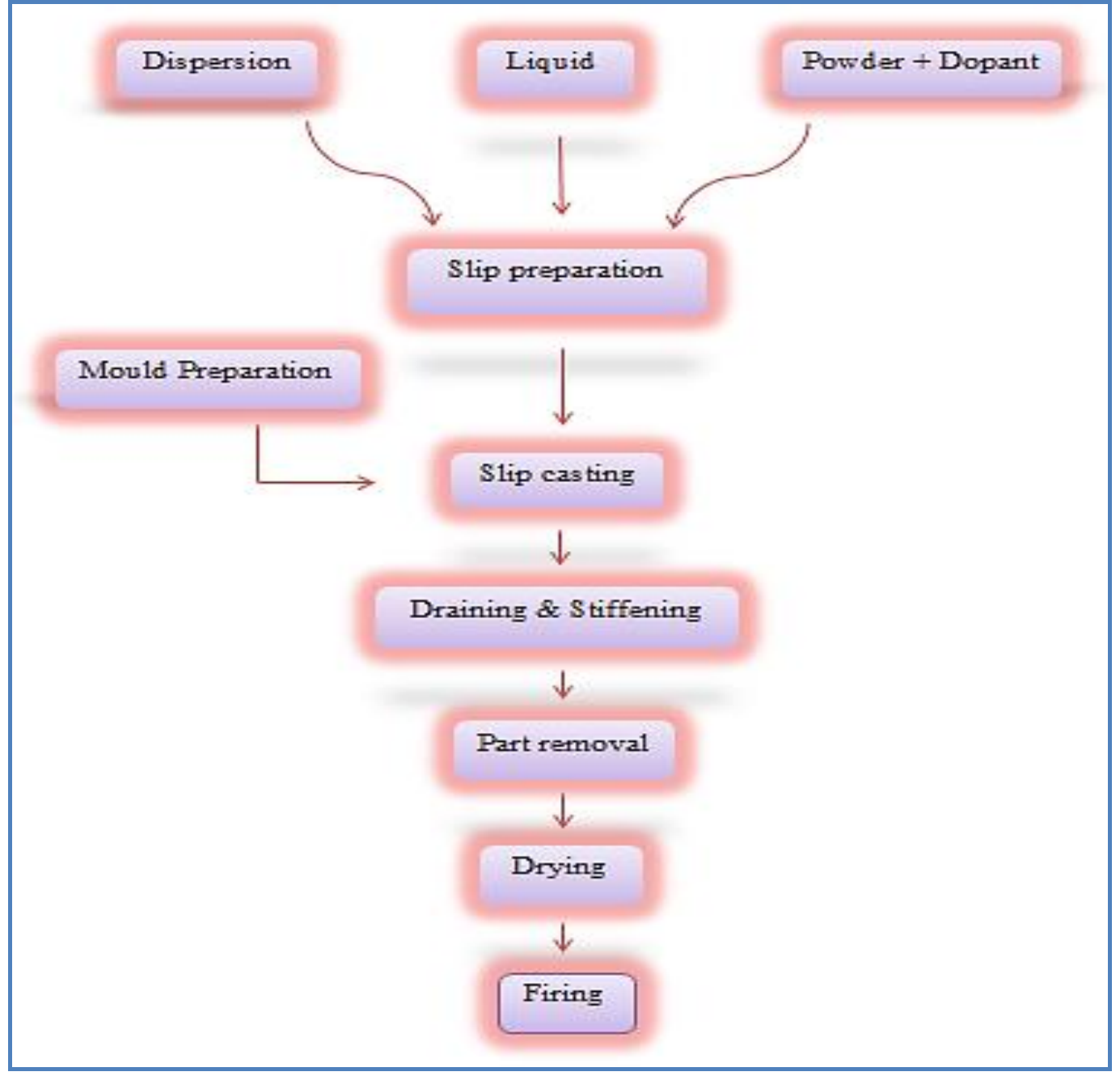

Figure (1): Flow chart of the slip casting process.

\section{1- Materials:}

The starting materials used for this work were a commercial micro Gamma Alumina powder $\left(\gamma-\mathrm{Al}_{2} \mathrm{O}_{3}\right)$ German origin, prepared by Merck Company with mean particle size $(10 \mu \mathrm{m})$ and Purity $(99.99 \%)$.

The dopant that used here was Kaolinite micro powder $\left(\mathrm{Al}_{2} \mathrm{Si}_{2} \mathrm{O}_{5}(\mathrm{OH})_{4}\right)$, prepared by (LTD Chemicals Dearborn) Company with mean particle size (20 $\mu \mathrm{m})$.

\section{2- Mould making:}

The plaster moulds were prepared using water and Plaster of Paris in the ratio (3:4), and then the prepared mixture was slowly poured into the hollow cubical box 
to a certain predefined height. The body is kept for air drying for about ( $2 \mathrm{~h})$. After $(2 \mathrm{~h})$ the body is removed from the wood box and kept for air drying for $(24 \mathrm{~h})$. Then the mould was kept in drier at (60 to 70) ${ }^{\circ} \mathrm{C}$ for complete removal of water deposited at the pores figure (2).
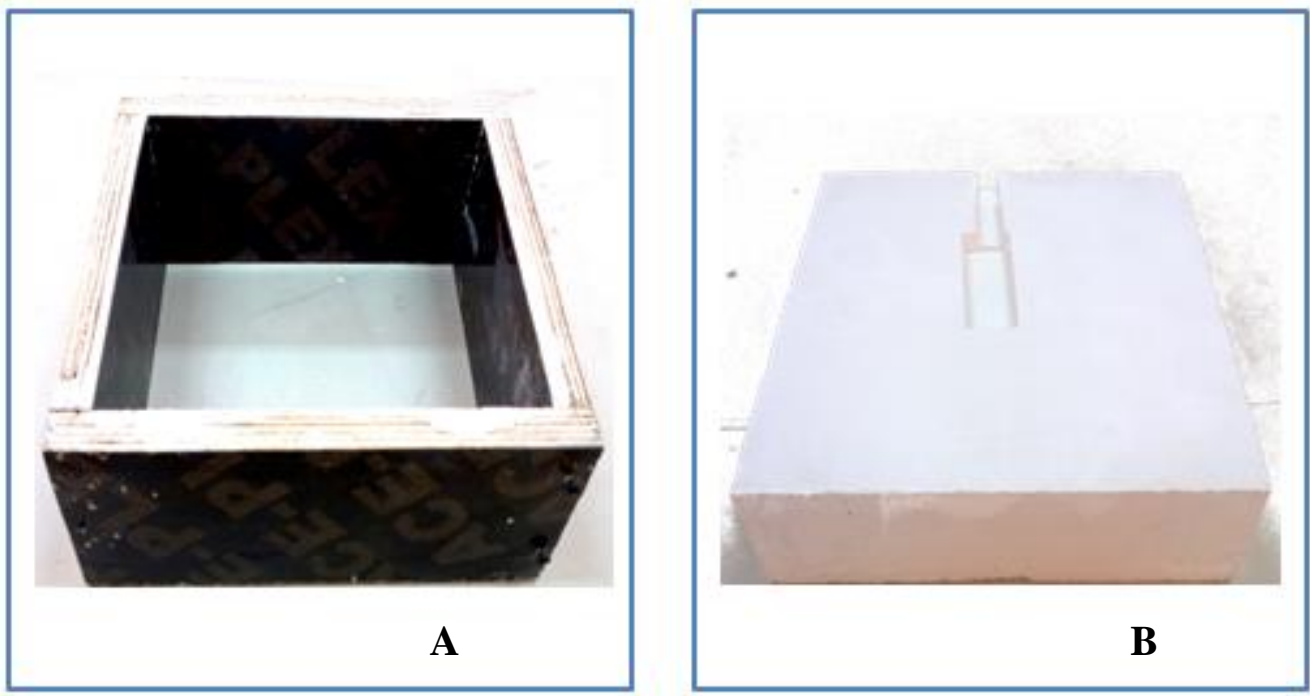

Figure (2): Mould preparation (A) and the mould prepared for a bar sample (B).

\section{3- Optimization of the Slurry:}

Optimization of the slip is necessary as it controls the stability, viscosity and many other casting phenomenon such as casing rates, defects generated during casting process and many more. The slurry is optimized by studying its properties so as to get a slip which is stable i.e. the suspended particles do not agglomerate or do not settle with changing time. The slip obtained by preparing samples with different dispersants and different percentage of dispersant. It was found experimentally that $(\mathrm{Na}-\mathrm{CMC})$ is the most prefer dispersant at the value of $(0.33$ $\mathrm{ml})$ for each gram of powder, when the density of (Na-CMC) solution is (1.17 $\left.\mathrm{g} / \mathrm{cm}^{3}\right)$. The alumina - kaolinite slurries solid content chosen to be (60 wt. \%), three different weight percentages of kaolinite to alumina $((5,10$ and 15$)$ wt. \%) was used. 


\section{4- Casting, Drying and Firing:}

Once the slip is prepared, it is casted in the plaster moulds. The casting method that was used here is both the solid casting and the drain casting methods.

After casting the body, the casted body was kept away from an air draft or under direct sunlight to dry at room temperature. After $(24 \mathrm{~h})$ the mould is tapped slowly so as to remove the casted bodies.

The casted body is kept for air drying either under direct sunlight or at room temperature depending on the initial strength of the body. Then the sample is transferred to oven (made by (JRAD) company) for oven drying which is kept at about $\left(60{ }^{\circ} \mathrm{C}\right)$ for $(24 \mathrm{~h})$. So overall the drying process takes near about (2-3) days. After the bodies have dried up they are brought into shape by polishing their surfaces using a sand paper. Now the sample is ready to be fired.

\section{5- Firing Program:}

The samples were fired in an English origin furnace made by (carbolite) company in three steps figure (3) [4]:

a) The first step: Temperature rising from the room temperature with a temperature raising speed of (10 $\left.{ }^{\circ} \mathrm{C} / \mathrm{min}\right)$ and settled at $\left(500{ }^{\circ} \mathrm{C}\right)$ for (2 hours).

b) The second step: Temperature rising with raising speed of (10 $\left.{ }^{\circ} \mathrm{C} / \mathrm{min}\right)$ from $\left(500{ }^{\circ} \mathrm{C}\right)$ and settled at $\left(1100{ }^{\circ} \mathrm{C}\right)$ for $(2$ hours $)$.

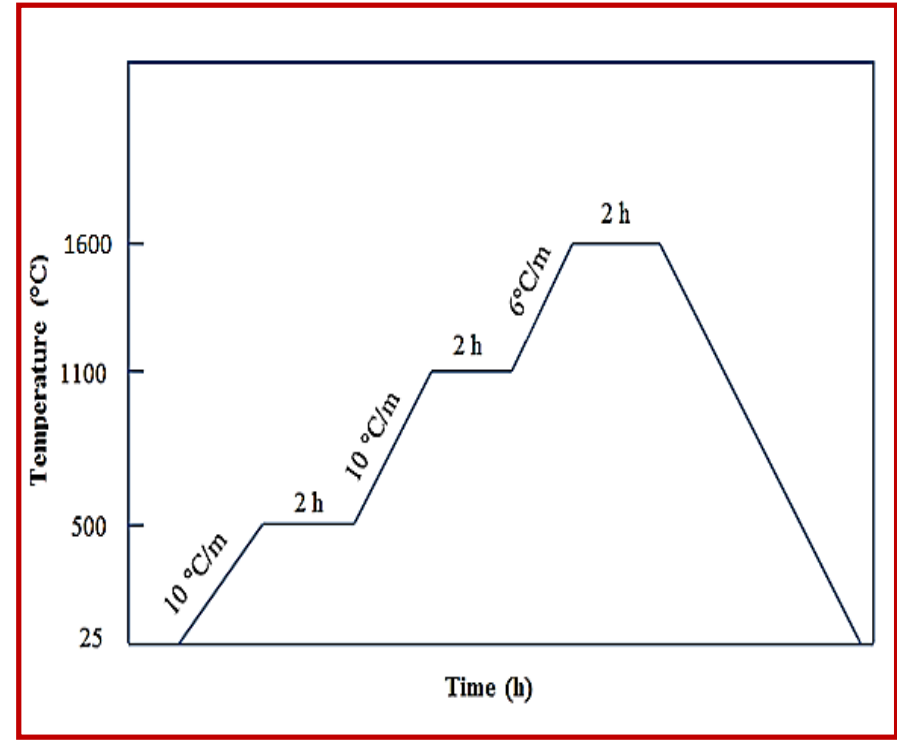

Figure (3): The firing

c) The third step: Temperature rising from $\left(1100{ }^{\circ} \mathrm{C}\right)$ with raising speed of $(6$ $\left.{ }^{\circ} \mathrm{C} / \mathrm{min}\right)$ and settled at $\left(1600{ }^{\circ} \mathrm{C}\right)$ for $(2$ hours $)$. 


\section{Procedure of Measurements:}

a- Bulk Density (BD), Apparent Porosity (\% AP) and Water Absorption (A):

These tests were determined according to the (ASTM C20 - 00) [6]. The Bulk Density was calculated by using equation (1), the apparent porosity (\% AP) was calculated by using equation (2) and the water absorption was calculated by using equation (3).

$$
\begin{gathered}
\% A \cdot P=\frac{\mathbf{W} \mathbf{s}-\mathbf{W d}}{W s-W i} * \mathbf{1 0 0} \\
B D=\frac{\mathbf{W d}}{W d-W i} \\
\% A=\frac{\mathbf{W} \mathbf{s}-\mathbf{W d}}{W d} * 100
\end{gathered}
$$

Where:

Wd: dry weights

Ws: soaked weights

Wi: immersed weights

\section{b- Thermal Conductivity:}

Lee's disk method is used to measure the thermal conductivity of the specimens. The Lee's disk apparatus made by (Griffin and George) company was used. The thermal conductivity calculated from the equation $(4)[7,8]$.

$$
K \frac{(T u-T m)}{d s}=h\left(T m+\frac{2}{r}\left(d m+\frac{1}{4} d s\right) T m+\frac{1}{2 r} d s T u\right)
$$

Where, $\left(\mathrm{T}_{\mathrm{U}}\right)$ : temperature of disk $(\mathrm{u}),\left(\mathrm{T}_{\mathrm{m}}\right)$ : temperature of disk $(\mathrm{m}),(\mathrm{r})$ : radius of the disk, $\left(\mathrm{d}_{\mathrm{m}}\right)$ : thickness of the disk $(\mathrm{m}),(\mathrm{ds})$ : thickness of the disk (s) (specimen) 
and (h): heat loss per $\left(\mathrm{second} / \mathrm{cm}^{2}\right)$ for one degree in excess of temperature of disk over that of the enclosure.

\section{c- Compressive Strength:}

(ASTM standard-C773) was used as a standard to test the compressive strength of ceramic specimens [9], and this compressive strength is calculated from equation (5) :

\section{Compressive Strength $=\frac{F}{A}$}

Where: (F) is the applied force and (A) is the area of the spacemen. The force was applied perpendicular and continuously on the specimen by using hydraulic testing compression machine, maximum force $(7.5 \mathrm{kN})$.

\section{d- Flexural Strength:}

Flexural strength was measured in a (3-point bending) test. The dimensions of bar-shaped specimens are $\left(6 \times 2 \times 1 \mathrm{~cm}^{3}\right)$, and equation (6) was used to calculate the bending strength for the specimens (ASTM C1674 - 11) [10].

$$
\text { Flexural strength }=\frac{3 F D}{2 b d^{2}}
$$

Where:

$\mathrm{b}, \mathrm{d}$ and $\mathrm{D}$ : are the dimensions of the sample and $\mathrm{F}$ is the force.

\section{e- Hardness:}

(TH210) Shore (D) hardness tester was used to measure the hardness of the high porous specimens (ASTM D2240 - 05) [11]. The hardness was calculated by taking the average of each surface hardness value of the specimens.

\section{Results and Discussion:}

Effects of Kaolinite additionson: 
Lower density of addition materials leading to decreasing the density of specimen. But here in the case of (alumina - kaolinite) slip casting the contrary was occurred, and that is a normal situation because of tow main reasons; the first is the low percentage addition of kaolinite $(5-15) \%$, and the second is the effect of casting rate which increase by the increasing of kaolinite ratio because of the plastic property of clay, and that lead to increase the density because of the high reduction of porosity during forming process $[12,13,14]$. Therefor the density is increasing with increasing of kaolinite and that is clear in figure (4) and this result consistent with the study [5] which shows the relation between physical properties and casting rate. Figure (5) and (6) shows the decreases of porosity and water absorption respectively with kaolin additions for the same cause.

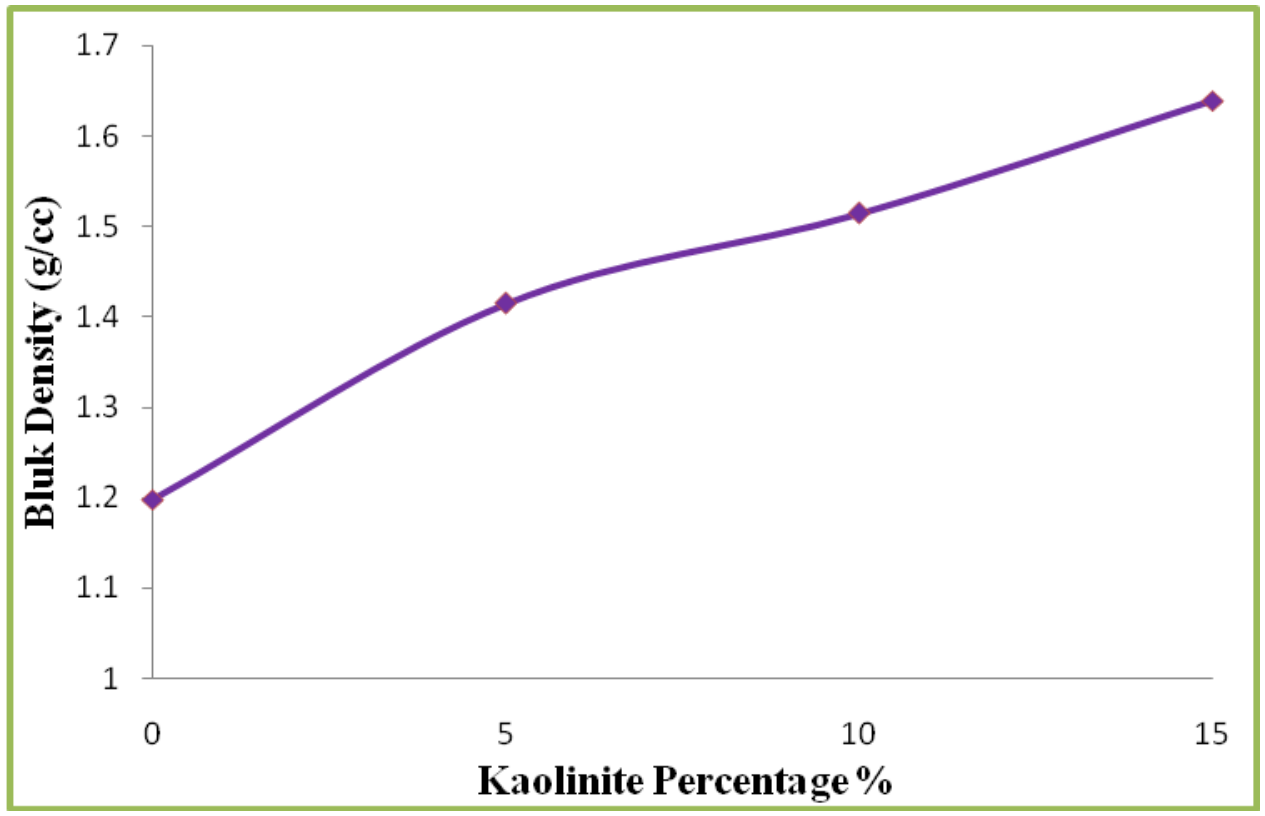

Figure (4): Effect of kaolinite percentage additions on bulk density. 


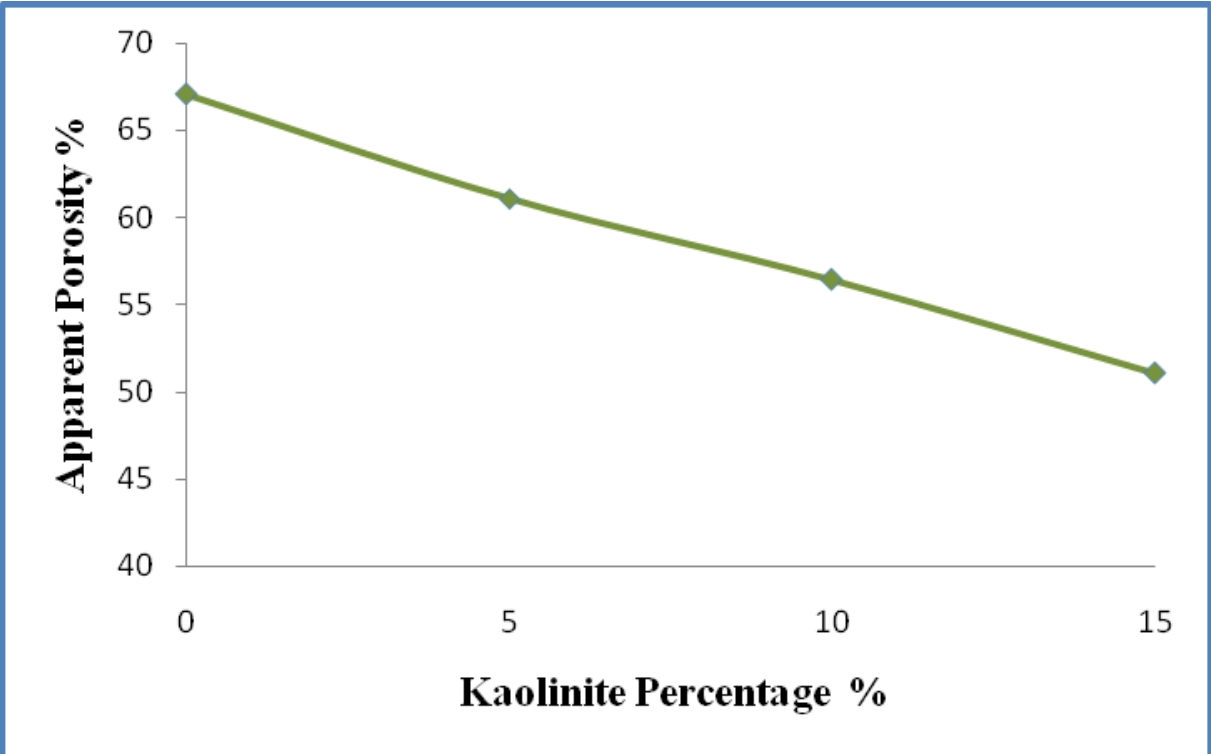

Figure (5): Effect of kaolinite percentage additions on apparent porosity.

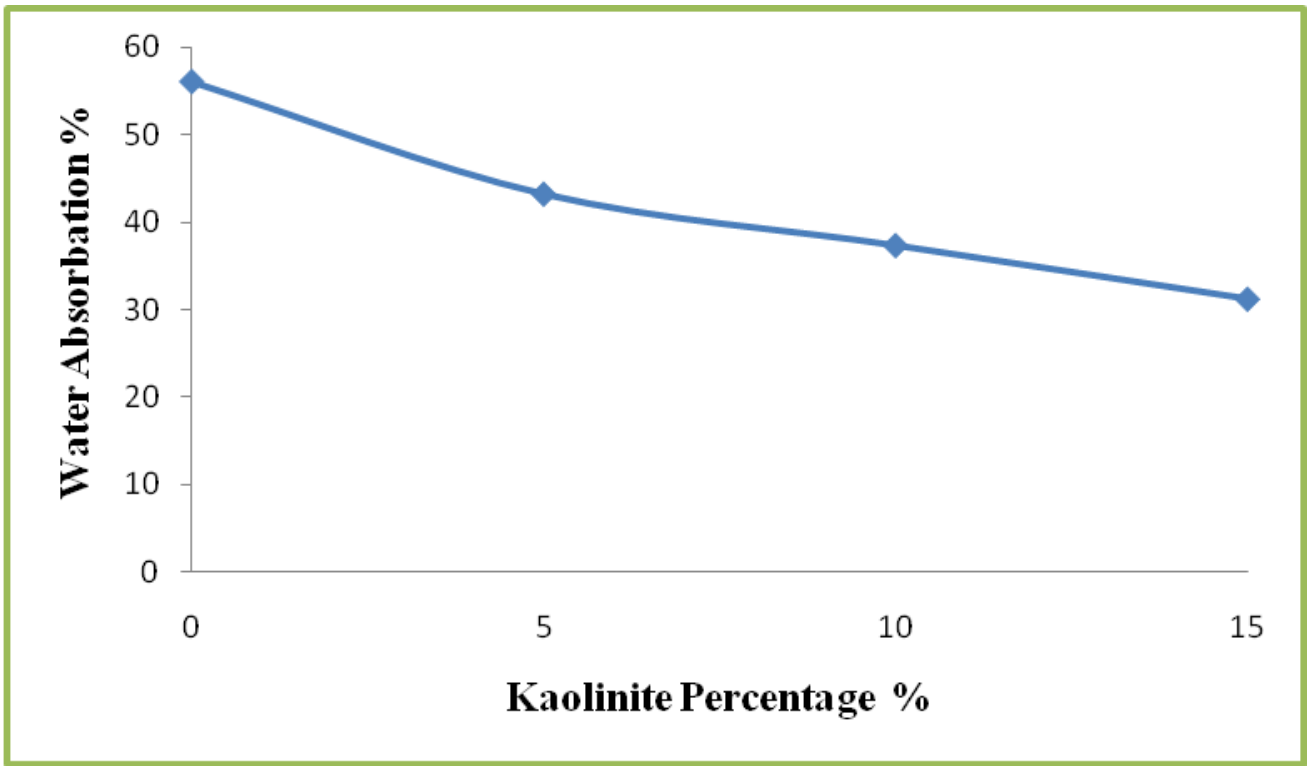

Figure (6): Effect of kaolinite percentage additions on water absorption.

\section{b- Thermal Conductivity:}

Thermal conductivity of alumina samples, naturally, decreases with clay additions [7]. But here the thermal conductivity increases with kaolinite additions, the main cause is the increase in kaolinite ratio leads to decrease in the porosity and consequently increase in thermal conductivity figure (7) and this result consistent with the stadies $[7,5]$ wich show the theremal Conductivity as function of physical properties. 


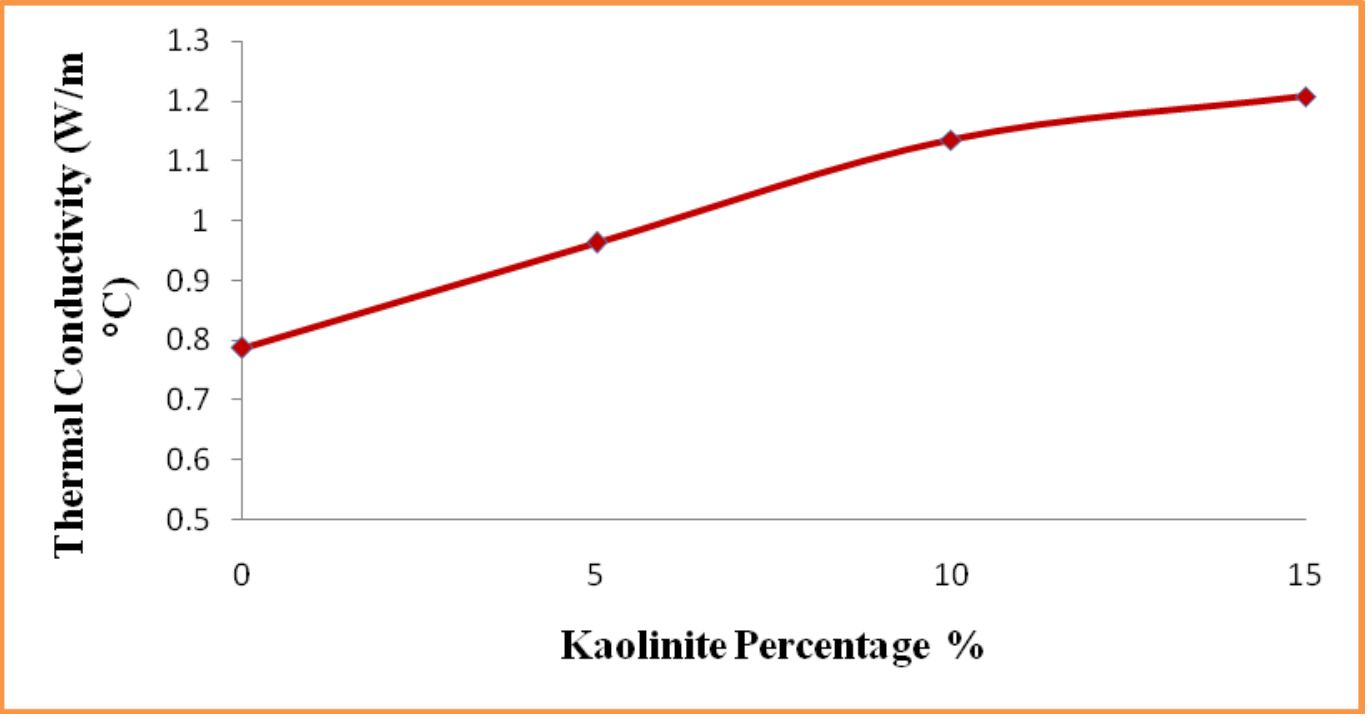

\section{Figure (7): Effect of kaolinite percentage additions on thermal conductivity.}

\section{c- Compressive Strength:}

The compressive strength increase with increasing kaolinite content figure (8). This This increase begins with comparatively large value (at 5\% addition) then increases in kaolinite addition leads to increase in the strength of ceramic products, because of the bigger amount of glass phase and higher density at the highr percentage of kaolinite [15, 16] and this result consistent with the stady [17] wich shows the michanical properties as function of physical properties. 


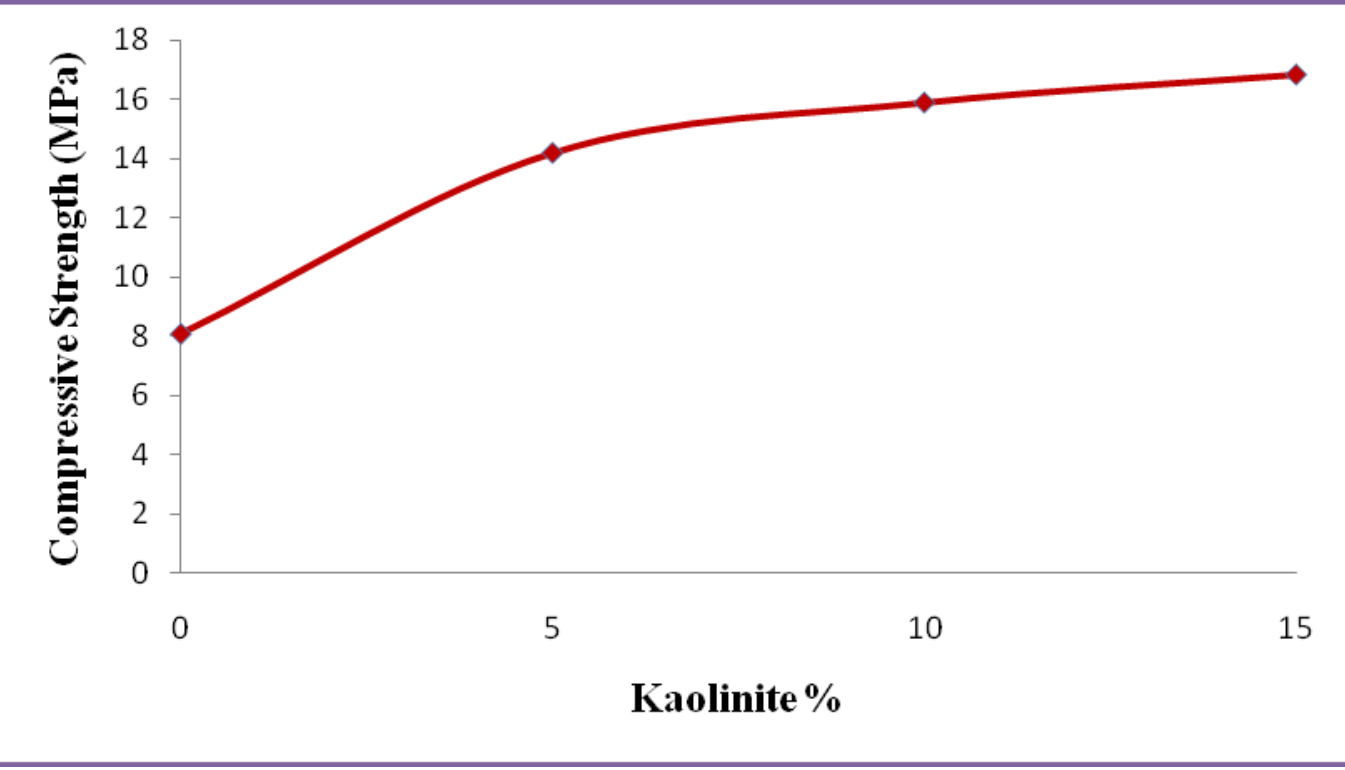

Figure (8): Effect of kaolinite percentage additions on compressive strength.

\section{d- Bending Strength:}

Bending Strength increases with clay addition which increases with a semilinear form as shown in figure (9), this is due to lower porpsity and higher density at the highr percentage of kaolinite $[7,15,16]$ and this result consistent with the stady [17] wich shows the michanical properties as function of physical properties. 


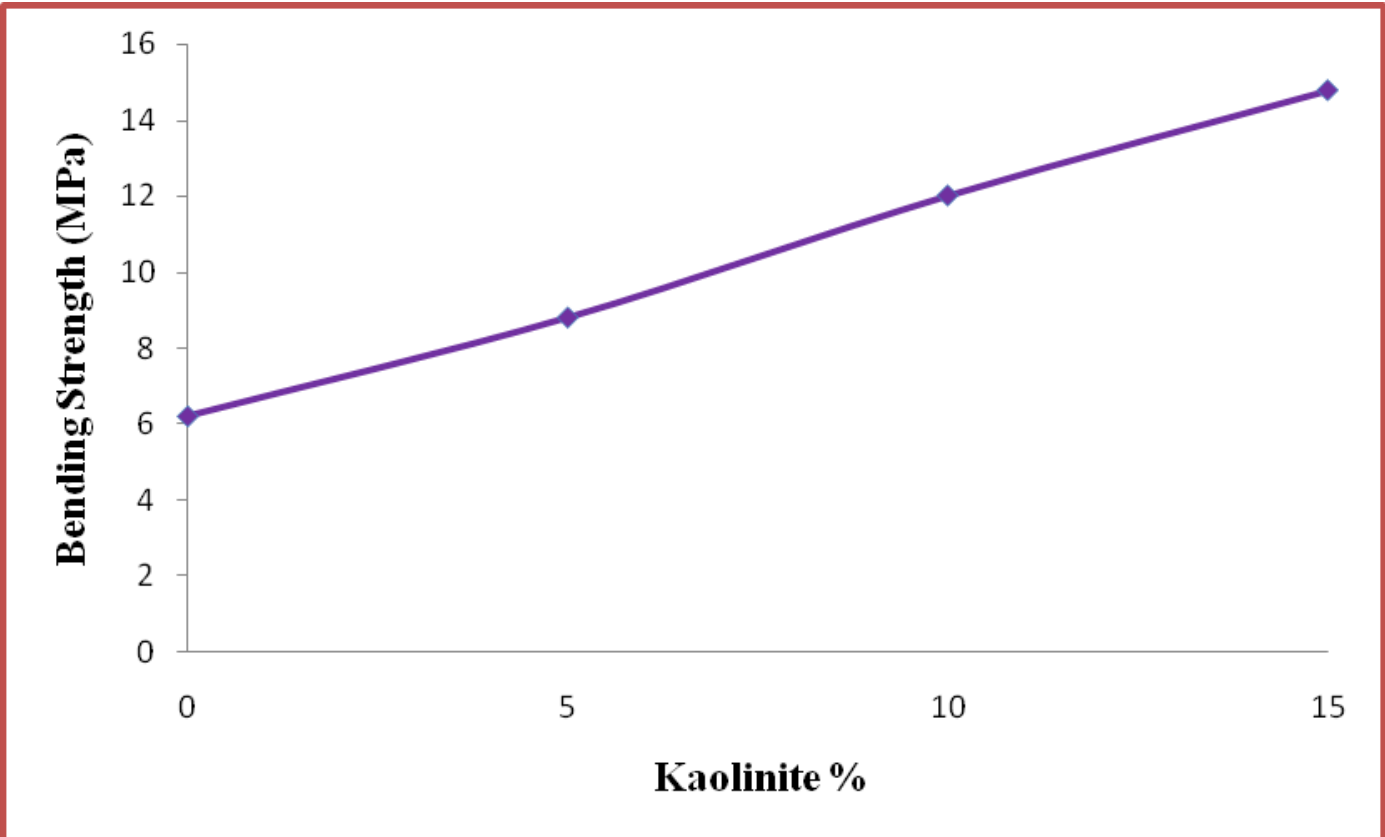

Figure (9): Effect of kaolinite percentage additions on bending strength.

\section{e- Hardness:}

Figure (10), shows the shore (D) hardness variations with kaolinite additions. Clearly, hardness increases when kaolinite addition is increased. Raising and lowering hardness can be explained on the basis of decreasing and increasing the porosity [7, 16] and this result consistent with the stady [17] wich shows the michanical properties as function of physical properties. This is an important factor affecting the hardness. This increasing of hardness lead to increase wear resistance in addition to increase abarasive resistance of ceramic products. 


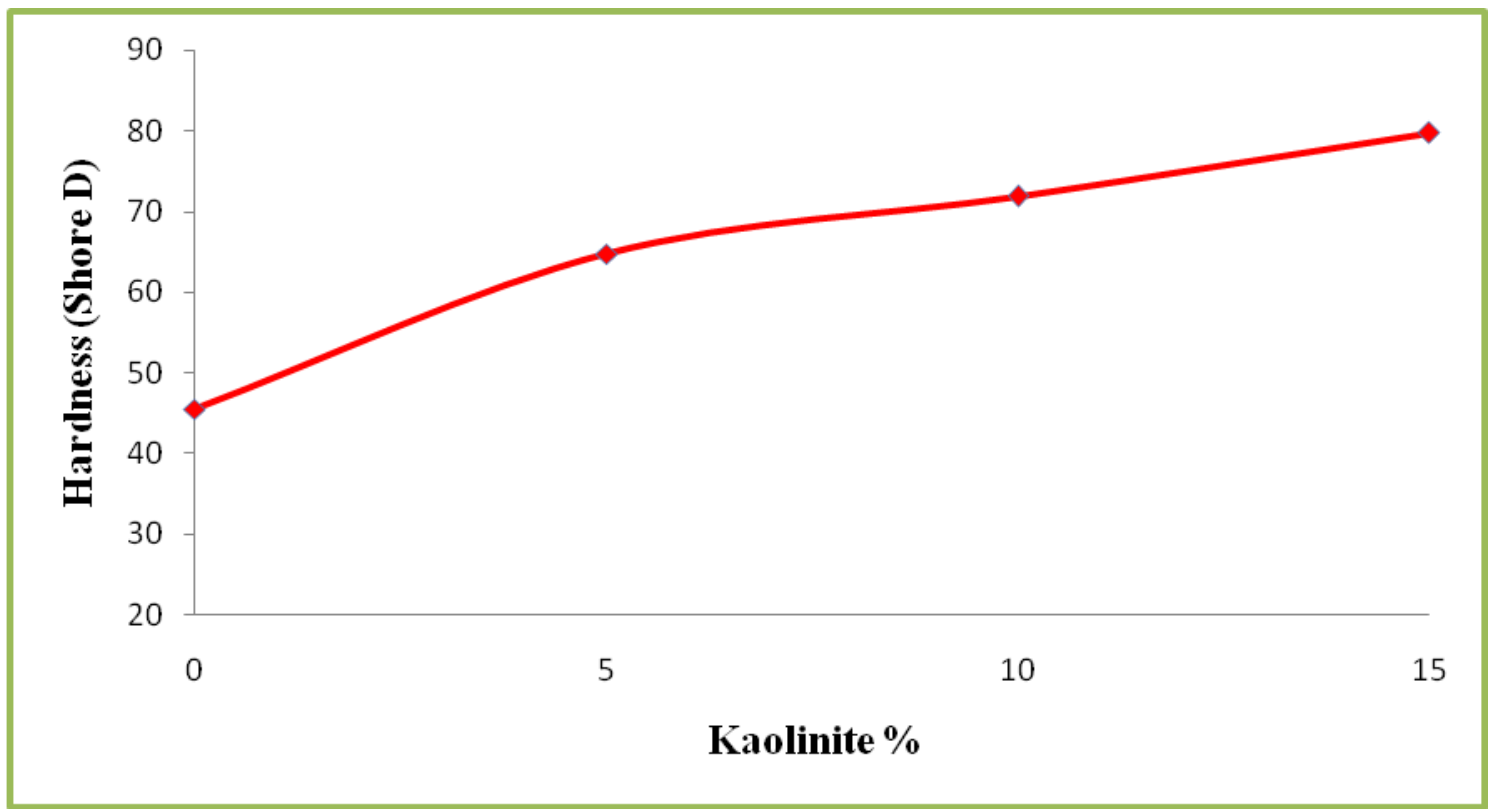

Figure (10): Effect of kaolinite percentage additions on hardness.

\section{Conclusions:}

The high values of porosity and low values of thermal conductivity of all samples make a possibility of using them in the thermal insulation, filters, light blocks and furnaces lining. Among many dispersants available here the (Na$\mathrm{CMC}$ ) act as a good dispersant and binder. The Kaolinite acts as a binder for the alumina particles.

The Kaolinite has lower density than alumina but it has plastic properties which lead to decrease the casting rate which lead to increase the density of the samples.

The mixing process of powders and water is very important because the powders uniform dispersion has a great effect on the strength of porous ceramic. 


\section{References:}

[1]. A. G. Lamas, M. Almeida and H. M. M. Diz, "Slip-casting of alumina bodies with differential porosities", Journal of the American Ceramic Society, Vol. 85, pp.3126-3132, (2002).

[2]. T. Natori, T. Shimaguchi and T. Yamada, "Method of forming cast article by slip casting", United states patent, Vol. 4, pp. 621 - 632, (1989).

[3]. J. S. Reed, Principles of Ceramics Processing, 2nd edition Wiley, New York, (1995).

[4]. O. Aladesuyi, M. Pal, S. K. Das and K. O. Ajanaku, "Phase and microstructural evolution during sintering of mixture of 75:25 Nigerian kaolin and calcined alumina powder compacts", Journal of Materials and Environmental Sciences, Vol. 8, No. 8, pp. 2682-2838, (2017).

[5]. M. Arif, S. K. Durrani1, M. Akram, N. Hussain and B. A. Hasan, "Fabrication of alumina wares by slip casting technology" Journal of Pak Mater Soc, Vol.5, No. 1, pp. 114-120, (2011).

[6]. ASTM C20 - 00, "Standard Test Methods for Apparent Porosity, Water Absorption, Apparent Specific Gravity, and Bulk Density of Burned Refractory Brick and Shapes by Boiling Water", (2010).

[7]. S. A. Z. Al-Jeboori, Ph.D. Thesis, University of Technology, (2005).

[8]. T. Akrill, G. Bennet and C. Millar, "Physics", Edward Arnold Publishers Ltd, London, pp.118-119, (1979).

[9]. ASTM C773 - 88, "Standard Test Method for Compressive (Crushing) Strength of Fired White ware Materials", Annual Book of ASTM Standards, (2011).

[10]. ASTM C1674 - 11, "Standard Test Method for Flexural Strength of Advanced Ceramics with Engineered Porosity at Ambient Temperatures", Annual Book of ASTM Standards, (2011).

[11]. ASTM D2240 - 05, "Standard Test Method for Rubber Property - Durometer 
Hardness", (2010).

[12]. Y. Zhang and J. Binner, "Enhanced casting rate by dynamic heating during slip casting "Journal of the European Ceramic Society, Vol. 22, pp. 135-142, (2002).

[13] C. Falamaki and M. Beyhaghi, "Slip casting process for the manufacture of tubular alumina microfiltration membranes "Materials Science-Poland, Vol. 27, No. 2, pp. 427-441, (2009).

[14]. H. Katsuki, J. Kim, S. Kim, J. Kim, J. Pee and W. Cho, "Influence of alumina content in the raw clay on the sintering behavior of Karatsu ware", Journal of the Ceramic Society of Japan, Vol. 124, No. 8, pp. 833-837, (2016).

[15]. J. S. Magdeski, "The porosity dependence of mechanical properties of sintered alumina", Journal of the University of Chemical Technology and Metallurgy, Vol. 45, No. 2, pp143-148, (2010).

[16]. A. Ouali, M. Heraiz, F. Sahnoune, H. Belhouchet, M. Fatmi and N. Saheb, "Effect of $\mathrm{MgO}$ addition on the mechanical and thermal properties of mullite synthesized through reaction sintering of $\mathrm{Al}_{2} \mathrm{O}_{3}$ and Algerian kaolin", American Journal of Modern Physics, Vol. 2, No. 5, pp. 270-275, (2013).

[17]. C. Y. Chen, G. S. Lan and W. H. Tuan, "Preparation of mullite by the reaction sintering of kaolinite and alumina", Journal of the European Ceramic Society, Vol. 20, pp. 2519-2525, (2000). 